\title{
Characteristics of Urban Streets and the Implications for the Structure of Cities
}

\author{
EDWIN S. BRIERLEY \\ De Montfort University \\ United Kingdom
}

\begin{abstract}
The paper presents the case that orthodox planning of urban areas in which an emphasis is placed upon the district plan implicitly misunderstands the characteristics of the urban street and the implications that such streets have for the structure of cities. Experiences of the city are often centred upon the street as a facet not only of the urban structure but also of the movement between districts and the variety of experiences that this facilitates. The paper, however, concludes that whereas the significance of urban streets is well established, in Britain they tend to be the legacy of previous centuries.
\end{abstract}

\section{THE TRADITION OF THE STREET}

Jane Jacobs in The Death and Life of Great American Cities written over forty years ago wrote that the aim of her book was 'an attack on the principles and aims that have shaped modern, orthodox city planning and rebuilding'. The argument developed in that book led, in a way, to a reappraisal of the orthodoxies of urban planning. A sub-text throughout the discussion is that of the concept of the street. 'The streets were alive with children playing, people shopping, people strolling, people talking... the general street atmosphere of buoyancy and friendliness was so infectious'

Traditionally in Britain the idea of the street has been central to understanding urbanity, particularly for those who experience the city as a path of streets and squares. Rowe and Koetter in their work Collage City regard memorable streets as 'possible objects trouves in the urbanistic collage'. Their thesis indicates the possibility of a rhetoric between public and private zones and a solid to ground plan which is characterised as urban form and urban space. In Britain, the morphology of urban form is created to a large extent by the typology of the terrace block and this is represented by the varying effects of urban space and the continuity in streetscape.

Willmott and Young in their studies of societal patterns in the East End of London ${ }^{3}$ emphasised the social relationships which were associated with the street. Arguably, however, the strength of the formal character of the street acts as a symbol for many people of the nature of urbanity.
Bernard Huet has observed that, 'To speak of urban form is not to ignore social and economic problems or believe that architecture by itself cannot constitute the space of the city. It is simply to acknowledge the dimensions of the visible in urban space, to work with a system of relations between urban form and architectural typology'4. The concept of architecture as a symbolic value needs to be contained in notions of the way we perceive urbanity.

Perceptions of urbanity have focussed to a large extent upon the definitions of urban areas. That approach may be considered to reflect an orthodox view of urban design. This has been at the expense of understanding the urban situation.The idea of action areas which are defined zones within the draft district plans of cities is a result of modernist planning ideals. Unfortunately the basis of such thinking is hermetic and excludes valuable aspects of city form. For instance the experiential awareness which may be gained from the variety of form and space associated with a path or route through the city which may pass through several districts but is arguably the significant form of urban identity. Imposed boundary conditions on the urban experience which result from district plans are not only a false means of controlling design but they also undervalue the richness of the juxtaposition of , at times, the disparate elements of the urban scene.

\section{THE URBAN PATH}

One of the most significant urban plans in Britain, without doubt, is that associated with Nash's proposals of the early nineteenth-century for Regent Street in London. The route passes through a number of districts from Regents Park to Whitehall and at the time of its design connected the rather seedy district of Soho with the elegance of Mayfair. Along the length of the street there is a sequence of quadrant, circus and place which creates a rich urban experience. At the time of its conception the proposals for Regent Street were both creative and innovative. For the idea of the street was to connect Marylebone Park, now known as Regent's Park, with the Charing Cross district and so on to the Government area of Whitehall. The plan required devising a route, or 
street, through the built-up area of central London. Parts of the route already existed, such as Portland Place, but were not part of a connecting route. The brilliance of Nash's plan was the way in which he was able to weave the route ,by means of circus and quadrant, through the centre of early nineteenth-century London. Nowhere, however, in contemporary thinking in Britain is that form of imaginative approach to be found and the 'objects trouves' of Rowe and Koetter in Britain are the legacy of previous centuries. Arguably recent proposals for the Kings Cross-St Pancras district of London afforded a similar opportunity but the vision and skill of Nash is absent.

There are many examples which already exist that may be used to illustrate the effect of the route or street on the character of the urban environment. In Leicester there is a pedestrian route which links the centre of town with a public park and the University. The route which is known as New Walk is illustrated in Alexander's A Pattern Language ${ }^{5}$. In a similar manner to Regent Street, New Walk in its present form dates from the Georgian period and is a splendid example of a pedestrian promenade. Fronting onto New Walk are the City Art Gallery, a number of offices, churches, houses, clubs and pubs. Quite clearly for most parts of the day and evening New Walk is a busy pedestrian way. The route draws people to this part of town and adjacent areas relate to the line of New Walk. Along the three-quarters of a mile promenade which is tree-lined there are three open spaces each having an individual character. There are two squares and an oval. The name New Walk is to an extent a misnomer, since it is claimed the route is originally from Roman times. In the last century New Walk was the main link from town to the horse racecourse. Thus New Walk satisfies many of the characteristics required of an urban route. It is one with a well defined purpose; it is one that is part of the memory of the town; it is both of the people, in terms of being in part a focus for entertainment, and for the people, in terms of the civic nature of aspects of the route such as the Art Gallery.

Yet. too often the consequences of the nature of the route for urban planning and the characteristics which would result are not investigated. This is in part a result of a functional approach to urban structure, yet when we think about the way that we describe and understand urbanity the process is more that of the narrative. In order to illustrate the way in which a narrative approach to the creation of urban form may progress, a parallel with London's Regent Street may be examined. If we take the urban situation of the area to the south of the main line railway stations at St Pancras and Kings Cross, the projected terminus for the cross channel rail link, there exists an ill defined area of the borough of Camden. At first sight, in terms of urban planning, the area is of social housing and buildings associated with the University. If, however, we allow the imagination to wander and discover the connections that may be made in the form of a narrative experience the search is revealing.

A pedestrian route or street may be imagined that would extend from St Pancras to the River Thames. That route would be a twenty minute walk, arguably along a tree lined avenue, or ten minutes by vehicle. The route would either pass by or be adjacent to University facilities, the Dickens' Museum, Teaching Hospitals, the Inns of Court, and the Soane Museum. Towards the Thames, a ten minute walk to the east would lead to St Paul's and a quarter an hour walk across the river to the west is the National Theatre. The street remains one of the imagination, but it may well be argued that such a defined route would alter the urban character of London far extended beyond the physical limits of the route. Clearly the definition of the urban situation not only in this area of London but in general needs a radical rethink, so that the pleasure of urban activity and experience becomes the significant criterion for city development rather than transportation policies alone.

\section{PERCEPTIONS OF THE CITY}

In order to appreciate the nature of this approach to urbanity it is necessary to understand the way people perceive the city. The urban situation is interpreted as a series of images or cluster of images which become interconnected in the mind. Rarely are they sequential, rather they become juxtaposed depending upon the way an individual appreciates the formal imagery and experiential quality of the urban scene. The approach to experiencing the city is an inductive one. It is an emotional one which quite clearly does not fit easily into the minds of orthodox planning schemes, which are often based upon analytical and socio-economic values.

One issue of some consequence which is raised by the formation of a route or street is the nature of the structure of the city. The nature of the discussion has been to argue against the precepts of formal rules for planning which do not take into account the narrative aspects of urban life. The idea of imposing a grid or network on the cities' form has been the focus of the reaction to the social and functionalist ideas of aspects of the modern movement. Alexander's work first published in the 1960s, "A City is not a Tree" recognised the failure of analysis in isolation, identified in functionalist planning, as a crude interpretation of the formal urban condition. The change in Alexander's thinking from the 1960 s to the 1970s, and Pattern Language, represented a movement from the scientific concept of space, in which deductive thought based upon evaluation is the criterion to ideas which were inductive in part based upon experience and possibly at times poetic. The essence of the more recent approach by Alexander is one of observation, perhaps in the manner of the flaneur, and of subjective experience.

Whilst this conceptual approach to rethinking aspects of urbanity appears relevant to our congested and often ill defined inner-city areas of today a new impetus for such thinking is needed. The examples quoted are from the past and indeed further examples which may be quoted are from past generations. In Europe we may think of the pedestrianisation of Copenhagen's main shopping thoroughfare or of the creation of the Lijnbaan in Rotterdam. Both 
from the immediate post-war period. In America, a scheme which comes to mind is that of the greenway notion in the 1956 Washington Square redevelopment plan in Philadelphia. The greenway idea was to tree line the avenues and squares to create axis that would link together the landmark buildings and squares. ${ }^{7}$

To an extent, the discussion so far has been historical in the examples quoted, but one purpose of this review of the nature of urbanity is to prepare the way for thinking in terms of conceptual approaches that both reflect the experiential qualities of the city and suggest ways of understanding city life. The difficulty encountered in relating the existing patterns of urbanity with imaginative thought on the nature of the urban route may be, in a way, indicated in the thinking of the Situationalists. Central to the thinking on the image of a route to the south of St Pancras which was developed earlier in the discussion is the idea raised in Situationist writing, that of the notion of imaginary maps of the real world. ${ }^{8}$

Essential to the ideas produced from the Situationists and to the awareness of Guy Debord, who arguably was the central figure of the movement, was the notion of the derive. This concept is based upon the idea of wandering or perhaps browsing through the city. The derive when described forms a narrative experience of the city. The connections formed in the mapping of the city by this means may appear to have a personalised or random quality. One of the features of this approach is that connections are made between various aspects of the city's life and form which whilst seemingly more frenetic than that of the street life of, for example, Jane Jacobs reveals an equal concern for experiencing the nature of the urban path.

\section{URBAN STREETS AND THE STRUCTURE OF CITIES}

The legacy of previous generations in the form of significant streets within cities may form a starting point for a reappraisal of the essential quality of urbanity that gives life to cities and the way we experience them. However, in order to achieve imaginative approaches to urban form the constraints of disciplinal viewpoints ought to reflect upon the narrative and experiential values.

If we return to Nash's Regent Street, we will find that the basis of the design thinking that Nash developed has similarities with aspects of the more contemporary approaches to urbanism. Those of the narrative and the journey through the city. The reason for the creation of the street was to connect the area of Marylebone Park, which is now known as Regent's Park, with Whitehall. At the time of its conception, there was no clear route through London along these lines. Yet, urban fragments existed. Whitehall had a long established urban character and Portland Place existed in isolation. If, we were to set the design problem today of connecting these disparate urban fragments, it would be interesting to speculate if the connections that Nash made would be repeated.

Arguably, in order to achieve such a solution a combination of arts and experimental techniques would be necessary to construct an integrated urban milieu. Here, in fact, is a paraphrase of a critique of the Situationist position. Hellevoet, the author of that critique, further develops the theory of 'unitary urbanism' which is central to the Situationist cause. 'This theory designates, contrary to modernist functionalism, the active participation in and experience of the social space of cities. It posits urban space as a playground where everyone interacts, and which everyone mentally recreates and constantly transforms. One participates in creating the urban environment as one discovers and constructs it'. 9

That recreation of the urban fabric was fundamental to the design problem, quoted previously, of the area south of $\mathrm{St}$ Pancras in London. The initial problem posed was that this area lacked character and identity. Yet, by transforming the problem the possibility of traversing London at this position became a solution and the route taken has parallels with that of Nash. When we investigate the nature of the urban fabric clearly we should not be constrained by district boundaries often arbitrarily formed. Rather the potential of the city, in terms of an urban experience should be developed by means of narrative insights into the concept of urban life and the movement of people through the city.

\section{REFERENCES}

1 Jacobs, Jane, The Death and Life of Great American Cities, Penguin Books, 1964, p19

2 Rowe C and Koetter F, Collage City, MIT Press 1982.

${ }^{3}$ Willmott $\mathrm{P}$ and Young M, Family and Kinship in East London, Penguin, London 1990 (Revised Ed).

${ }^{4}$ Huet, Bernard, 'The City as dwelling space: Alternatives to the Charter of Athens', Lotus, No 41, 1984.

5 Alexander, Christopher et al, A Pattern Language, Oxford University Press, 1977, p260.

${ }^{6}$ Alexander, Christopher, $A$ City is not a Tree, in; Thackara, J (Ed), Design After Modernism, Thames and Hudson, London 1988. pp 67-83.

7 Morris, Eleanor Smith, 'The Planning of Philadelphia', Architectural Design, London, August 1962.

${ }^{8}$ Sussman Elisabeth (Ed), On the Passage of a few people through a rather brief moment in time: The Situationist International 1957-1972, MIT Press,1991, pp133

${ }^{9}$ Hellevoet, Christel, 'Wandering in the City' in: The Power of the City/The City of Power, Whitney Museum of Art, New York, 1992, p32.

The paper is a result of work in the Architectural Theories and Urban Form Unit of the Graduate Programme. 